\title{
Arenimonas malthae sp. nov., a gammaproteobacterium isolated from an oil- contaminated site
}

\author{
Correspondence \\ Peter Kämpfer \\ peter.kaempfer@agrar.uni- \\ giessen.de
}

\author{
Chiu-Chung Young, ${ }^{1}$ Peter Kämpfer, ${ }^{2}$ Mann-Jing Ho, ${ }^{1}$ \\ Hans-Jürgen Busse, ${ }^{3}$ Birgit E. Huber, ${ }^{3}$ A. B. Arun, ${ }^{1}$ Fo-Ting Shen, ${ }^{1}$ \\ Wei-An Lai ${ }^{1}$ and P. D. Rekha ${ }^{1}$ \\ ${ }^{1}$ College of Agriculture and Natural Resources, Department of Soil and Environmental Sciences, \\ National Chung Hsing University, Taichung 402, Taiwan, ROC \\ ${ }^{2}$ Institut für Angewandte Mikrobiologie, Justus-Liebig Universität Giessen, \\ Heinrich-Buff-Ring 26-32 (IFZ), D-35392 Giessen, Germany \\ ${ }^{3}$ Institut für Bakteriologie, Mykrologie und Hygiene, Veterinärmedizinische Universität, \\ Veterinärplatz 1, A-1210 Wien, Austria
}

Kwon et al. (2007) isolated a Gram-negative organism from seashore sand for which they proposed the genus Arenimonas, represented by the single species Arenimonas donghaensis. During the characterization of micro-organisms from diesel-oil-contaminated soil samples taken near an oil refinery located in Chyai county, (Taiwan), strain CC-JY $-1^{\mathrm{T}}$ was isolated after incubation on nutrient agar at $32{ }^{\circ} \mathrm{C}$ for 3 days. Subcultivation was done on tryptone soy agar (TSA; Oxoid) at $30{ }^{\circ} \mathrm{C}$ for between 1 and 3 days.

Cell morphology of the isolate was observed under a Zeiss light microscope at $\times 1000$ magnification using cells grown for $24 \mathrm{~h}$ at $30{ }^{\circ} \mathrm{C}$ on nutrient agar (Oxoid). Gram-staining was performed as described by Gerhardt et al. (1994). Results on the cell morphology are given in the species description.

Physiological characteristics were studied according to Kämpfer (1990) and Kämpfer et al. (1991). In addition, the

The GenBank/EMBL/DDBJ accession number for the $16 \mathrm{~S}$ rRNA gene sequence of strain CC-JY- $1^{\top}$ is DQ239766.

A two-dimensional thin-layer chromatogram of the polar lipids of strain CC-JY $-1^{\top}$ is available as supplementary material with the online version of this paper. following test kits were used according to the instructions of the manufacturer: Biolog GN2 (Biolog), API ZYM (bioMérieux) and API 20E (bioMérieux). Antibiotic susceptibility testing was carried out using ATB STAPH 5 strips (bioMérieux) according to the manufacturer's recommendations. Presence of flexirubin-like pigments was examined by flooding the plates with $20 \%(\mathrm{w} / \mathrm{v})$ potassium hydroxide (Fautz \& Reichenbach, 1980). Fluorescence was tested after plating on King's B medium (King et al., 1954) after $48 \mathrm{~h}$.

On nutrient agar, strain CC-JY1 $1^{\mathrm{T}}$ was able to grow at 15 $36{ }^{\circ} \mathrm{C}$, but not at 40 or $10{ }^{\circ} \mathrm{C}$. The organism was able to grow on nutrient agar, TSA and R2A agar (all from Oxoid). No flexirubin-like pigments were observed. Strain CC-JY$1^{\mathrm{T}}$ was not able to produce acid from various carbohydrates; however, carbon substrate utilization tests with organic acids as substrates showed a few positive results. In the API 20E (bioMérieux) test system, strain CC-JY- ${ }^{\mathrm{T}}$ was only positive for the Voges-Proskauer test (acetoin production), gelatinase and arginine dihydrolase while, in API ZYM enzyme profiling, strain CC-JY- $1^{\mathrm{T}}$ was positive for alkaline and acid phosphatases, esterase, esterase lipase, leucine arylamidase, trypsin, $\alpha$-chymotrypsin and 
Table 1. Differentiating physiological characteristics of Arenimonas type strains

+ , Positive; - , negative; $(+)$ weakly positive. Both strains were positive in API ZYM tests for alkaline phosphatase, esterase (C4), esterase lipase (C8), trypsin, $\alpha$-chymotrypsin, acid phosphatase and naphthol-AS-BI-phosphohydrolase and negative for lipase (C14), valine arylamidase, cystine arylamidase, $\alpha$-galactosidase, $\beta$-galactosidase, $\beta$-glucuronidase, $\alpha$-glucosidase, $\beta$-glucosidase, $N$-acetyl- $\beta$-glucosaminidase, $\alpha$-mannosidase and $\alpha$-fucosidase.

\begin{tabular}{|c|c|c|}
\hline Characteristic & $\begin{array}{l}\text { A. malthae } \\
\text { CC-JY-1 }\end{array}$ & 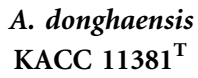 \\
\hline \multicolumn{3}{|l|}{ API ZYM test } \\
\hline Leucine arylamidase & + & - \\
\hline \multicolumn{3}{|l|}{ Biochemical tests } \\
\hline Acetoin production & + & - \\
\hline Arginine dihydrolase & + & - \\
\hline Phenylalanine deaminase & $(+)$ & - \\
\hline Nitrate reduction & + & - \\
\hline
\end{tabular}

naphthol-AS-BI-phosphohydrolase. More detailed results of the physiological characterization are given in the species description and in Table 1.

The 16S rRNA gene was analysed as described previously (Kämpfer et al., 2003; Young et al., 2005). Analysis of the sequence data was performed by using the software package MEGA version 2.1 (Kumar et al., 2001) after multiple alignments of data by CLUSTAL_X (Thompson et al., 1997). A distance matrix method (distance options according to the Kimura two-parameter model), including clustering by neighbour-joining (Fig. 1), and a discrete character-based maximum-parsimony method were used (Kumar et al., 2001). In each case, bootstrap values were calculated based on 1000 replications. The 16S rRNA gene sequence of strain CC-JY- $1^{\mathrm{T}}$ was 1488 bp long. Sequence similarity calculations indicated that strain CC-JY- ${ }^{\mathrm{T}}$ showed the highest degree of similarity to Arenimonas donghaensis HO3-R $19^{\mathrm{T}}(96.7 \%)$. Lower sequence similarities $(<94 \%)$ were found with all other genera and species shown in Fig. 1.

For quinone and polar lipid analysis, cells were grown on PYE medium (Busse et al., 2005). The content of respiratory quinones was determined as described previously (Tindall, 1990; Altenburger et al., 1996) but using an HPLC consisting of a JASCO PU 2080 Plus pump and JASCO UV-2075 Plus UV/Vis detector. The predominant quinone was ubiquinone Q-8, which is a characteristic trait of members of the related genera Xanthomonas, Stenotrophomonas and Thermomonas (Yokota et al., 1992; Busse et al., 2002). The polar lipid profile of CC-JY-1 ${ }^{\mathrm{T}}$ (Supplementary Fig. S1, available in IJSEM Online) consisted of the major compounds diphosphatidylglycerol, phosphatidylglycerol and phosphatidylethanolamine, moderate to minor amounts of phosphatidylmonomethylethanolamine, two unknown phospholipids, one unknown aminolipid and two unknown polar lipids and trace amounts of one unknown phospholipid and three unknown aminolipids.

The polyamines were analysed as described by Busse \& Auling (1988) and Busse et al. (1997) but a JASCO PU 2080 Plus pump was employed. Strain CC-JY- $1^{\mathrm{T}}$ exhibited a polyamine pattern which was very similar to those of Thermomonas and Xanthomonas species (Auling et al., 1991; Yang et al., 1993; Busse et al., 2002), consisting of the predominant compound spermidine $[38.2 \mu \mathrm{mol}$ (g dry weight $\left.)^{-1}\right]$, minor amounts of spermine and putrescine $[1.8$ and $0.4 \mu \mathrm{mol}$ (g dry weight $)^{-1}$, respectively] and trace amounts of 1, 3-diaminopropane.

Fatty acid analyses were performed according to Kämpfer \& Kroppenstedt (1996) for strain CC-JY- ${ }^{\mathrm{T}}$ and $A$. donghaensis KACC $11381^{\mathrm{T}}$. The results are shown in Table 2.

DNA for the determination of the $\mathrm{G}+\mathrm{C}$ content was isolated by using the UltraClean microbial DNA isolation Kit (MOBIO), following the instructions supplied by the manufacturer. The $\mathrm{G}+\mathrm{C}$ content of DNA was calculated as

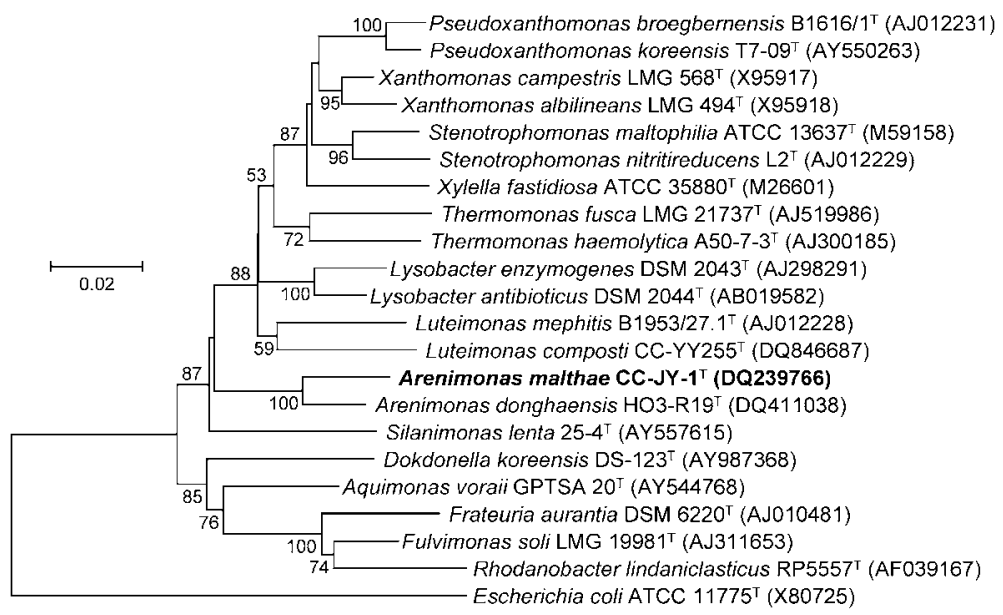

http://ijs.sgmjournals.org
Fig. 1. Phylogenetic analysis based on $16 \mathrm{~S}$ rRNA gene sequences available from the EMBL database (accession numbers given in parentheses) constructed after multiple alignments of data by CLUSTAL_x (Thompson et al., 1997). Distances (distance options according to the Kimura-2 model) were calculated and clustering with the neighbour-joining method was performed by using the software package MEGA version 2.1 (Kumar et al., 2001). Bootstrap values based on 1000 replications are listed as percentages at the branching points. Bar, 0.02 substitutions per nucleotide position. 
Table 2. Fatty acid profiles (\%) of the type strains of the genus Arenimonas

\begin{tabular}{|c|c|c|}
\hline Fatty acid & $\begin{array}{l}\text { A. malthae } \\
\text { CC-JY-1 }^{\mathrm{T}}\end{array}$ & 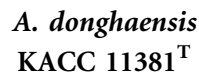 \\
\hline $11: 0$ iso & 2.0 & 3.8 \\
\hline $11: 0$ iso $3-\mathrm{OH}$ & 5.1 & 7.9 \\
\hline $13: 0$ iso & 0.3 & - \\
\hline $14: 0$ iso & 0.9 & 1.2 \\
\hline $14: 0$ & 0.6 & 1.0 \\
\hline $15: 1$ iso $F$ & 3.0 & 2.1 \\
\hline $15: 0$ iso & 43.0 & 37.6 \\
\hline $15: 0$ anteiso & 0.7 & - \\
\hline $16: 0$ iso & 6.5 & 10.2 \\
\hline $16: 0$ & 1.4 & 1.5 \\
\hline $17: 1$ iso $\omega 9 c$ & 25.8 & 24.3 \\
\hline $17: 0$ iso & 8.0 & 8.0 \\
\hline $17: 0$ anteiso & 0.2 & - \\
\hline Summed feature $1^{*}$ & 0.4 & 1.0 \\
\hline Summed feature $3^{\star}$ & 1.7 & 1.3 \\
\hline
\end{tabular}

${ }^{*}$ Summed feature 1 contains $15: 1$ iso $\mathrm{H}$ and/or 13:0 3-OH. Summed feature 3 contains $16: 1 \omega 7 c$ and/or $15: 0$ iso $2-\mathrm{OH}$.

previously published (Peña et al., 2005). DNA-DNA hybridization was carried out according to the method described by Ziemke et al. (1998) with A. donghaensis KACC $11381^{\mathrm{T}}$, resulting in a mean DNA-DNA relatedness of $32 \%$.

Strain CC-JY $-1^{\mathrm{T}}$ is clearly different from $A$. donghaensis, in both phenotype (differential biochemical tests are given in Table 1) and genotype, and represents a second member of the genus Arenimonas, for which we propose the name Arenimonas malthae sp. nov.

\section{Description of Arenimonas malthae sp. nov.}

Arenimonas malthae (mal.tha'e. L. fem. n. maltha a kind of thick petroleum; L. gen. n. malthae of petroleum, because the type strain was isolated from an oil-contaminated site).

Cells are Gram-negative, aerobic, motile and rod-shaped. Reproduction of cells is by division and not by budding. Oxidase-, acetoin- and catalase-positive; shows an aerobic metabolism. Good growth occurs after $48 \mathrm{~h}$ incubation on TSA and nutrient agar at $30{ }^{\circ} \mathrm{C}$. Colonies on complex standard media at $37^{\circ} \mathrm{C}$ are transparent to brownish, circular, smooth and convex with entire edges. No flexirubin-like pigments or fluorescence are formed. Major polyamine is spermidine. Ubiquinone Q-8 is the predominant respiratory quinone. The polar lipid profile consists of the major compounds diphosphatidylglycerol, phosphatidylglycerol and phosphatidylethanolamine. Moderate to minor amounts of phosphatidylmonomethylethanolamine, two unknown phospholipids, one unknown aminolipid and two unknown polar lipids and trace amounts of one unknown phospholipid and three unknown aminolipids are present. The fatty acid profile of the type strain is as follows: (percentages in parentheses): $\mathrm{C}_{11: 0}$ iso (2.0), $\mathrm{C}_{11: 0}$ iso 3-OH (5.1), $\mathrm{C}_{13: 0}$ iso (0.3), $\mathrm{C}_{14: 0}$ iso (0.9), $\mathrm{C}_{14: 0}(0.6), \mathrm{C}_{15: 1}$ iso $\mathrm{F}(3.0), \mathrm{C}_{15: 0}$ iso (43.0), $\mathrm{C}_{15: 0}$ anteiso (0.7), $\mathrm{C}_{16: 0}$ iso (6.5), summed feature 3 $\left(\mathrm{C}_{16: 1} \omega 7 c\right.$ and/or $\mathrm{C}_{15: 0}$ iso $\left.2-\mathrm{OH}\right)(1.7), \mathrm{C}_{16: 0}$ (1.4), iso $\mathrm{C}_{17: 1} \omega 9 c$ (25.8), $\mathrm{C}_{17: 0}$ iso (8.0) and $\mathrm{C}_{17: 0}$ anteiso (0.2). The type strain utilizes fumarate, propionate, glutarate, pyruvate, L-alanine, L-aspartate, L-leucine, L-proline, Lserine and DL-3-hydroxybutyrate, utilizes L-phenylalanine weakly and is unable to utilize acetate, cis-aconitate, Lmalate and mesaconate after 7 days of incubation. The following carbon sources are oxidized (positive with the Biolog GN2 system): glycogen, pyruvic acid methyl ester, $\beta$-hydroxybutyric acid, L-alaninamide, L-alanine, L-alanyl glycine, L-aspartic acid, L-glutamic acid, glycyl L-glutamic acid, L-proline, L-serine, $\alpha$-ketovaleric acid (weakly), succinamic acid (weakly), L-phenylalanine (weakly) and L-asparagine (weakly). The following substrates are not utilized as carbon sources: dextrin, $\alpha$-cyclodextrin, Tween 40, Tween 80, $N$-acetyl-D-glucosamine, $N$-acetyl-D-galactosamine, adonitol, L-arabitol, D-cellobiose, i-erythritol, Dfructose, L-fructose, D-galactose, gentiobiose, $\alpha$-D-glucose, myo-inositol, $\alpha$-D-lactose, lactulose, maltose, D-mannitol, D-melibiose, methyl $\beta$-D-glucoside, D-psicose, D-raffinose, L-rhamnose, D-sorbitol, sucrose, trehalose, turanose, xylitol, succinic acid monomethyl ester, acetic acid, cis-aconitic acid, citric acid, formic acid, D-galactonic acid lactone, Dgalacturonic acid, D-gluconic acid, D-glucosaminic acid, Dglucuronic acid, $\alpha$-hydroxybutyric acid, $\gamma$-hydroxybutyric acid, $p$-hydroxyphenylacetic acid, itaconic acid, $\alpha$-ketobutyric acid, $\alpha$-ketoglutaric acid, DL-lactic acid, malonic acid, propionic acid, quinic acid, D-saccharic acid, sebacic acid, succinic acid, bromosuccinic acid, glucuronamide, Dalanine, L-histidine, hydroxy-L-proline, L-leucine, Lornithine, L-pyroglutamic acid, D-serine, L-threonine, DLcarnitine, $\gamma$-aminobutyric acid, urocanic acid, inosine, uridine, thymidine, phenylethylamine, putrescine, 2-aminoethanol, 2,3-butanediol, glycerol, DL- $\alpha$-glycerol phosphate, $\alpha$-D-glucose 6-phosphate and D-glucose 6phosphate. Aesculin is not hydrolysed. Positive tests (API ZYM) are observed for arginine dihydrolase, alkaline phosphatase, esterase, esterase lipase, leucine arylamidase, trypsin, $\alpha$-chymotrypsin, acid phosphatase and naphtholAS-BI-phosphohydrolase, with negative results for lipase, valine arylamidase, cystine arylamidase, $\alpha$-galactosidase, $\beta$ galactosidase, $\beta$-glucuronidase, $\alpha$-glucosidase, $\beta$-glucosidase, $N$-acetyl- $\beta$-glucosaminidase, $\alpha$-mannosidase and $\alpha$ fucosidase. The type strain is sensitive to gentamicin, erythromycin, tetracycline, minocycline, rifampicin, norfloxacin and levofloxacin, while it is resistant to penicillin, cotrimoxazole, plindamycin, vancomycin, teicoplanin, quinupristin-dalfopristin, coag(-)oxacillin and oxacillin. The $\mathrm{G}+\mathrm{C}$ content of the type strain is $70.4 \mathrm{~mol} \%$.

The type strain is CC-JY- $1^{\mathrm{T}}\left(=\mathrm{CCUG} 53596^{\mathrm{T}}=\mathrm{CIP}\right.$ $\left.109310^{\mathrm{T}}\right)$, isolated from a diesel-oil-contaminated soil sample. 


\section{Acknowledgements}

This research work was kindly supported by a grant from the Ministry of Economic Affairs and National Science Council, Taiwan, ROC. We thank W. S. Huang for technical assistance, Jean Euzéby for his advice with the nomenclature and Dr B.-Y. Kim for providing A. donghaensis KACC $11381^{\mathrm{T}}$ prior to publication.

\section{References}

Altenburger, P., Kämpfer, P., Makristathis, A., Lubitz, W. \& Busse, H.-J. (1996). Classification of bacteria isolated from a medieval wall painting. J Biotechnol 47, 39-52.

Auling, G., Busse, H.-J., Pilz, F., Webb, L., Kneifel, H. \& Claus, D. (1991). Rapid differentiation by polyamine analysis of Xanthomonas strains from phytopathogenic pseudomonads and other members of the class Proteobacteria interacting with plants. Int J Syst Bacteriol 41, 223-228.

Busse, J. \& Auling, G. (1988). Polyamine pattern as a chemotaxonomic marker within the Proteobacteria. Syst Appl Microbiol 11, 1-8.

Busse, H.-J., Bunka, S., Hensel, A. \& Lubitz, W. (1997). Discrimination of members of the family Pasteurellaceae based on polyamine patterns. Int J Syst Bacteriol 47, 698-708.

Busse, H.-J., Kämpfer, P., Moore, E. R. B., Nuutinen, J., Tsitko, I. V., Denner, E. B. M., Vauterin, L., Valens, M., Rosselló-Mora, R. \& Salkinoja-Salonen, M. S. (2002). Thermomonas haemolytica gen. nov., sp. nov., a gammaproteobacterium from kaolin slurry. Int J Syst Evol Microbiol 52, 473-483.

Busse, H.-J., Hauser, E. \& Kämpfer, P. (2005). Description of two novel species, Sphingomonas abaci sp. nov. and Sphingomonas panni sp. nov. Int J Syst Evol Microbiol 55, 2565-2569.

Fautz, E. \& Reichenbach, H. (1980). A simple test for flexirubin-type pigments. FEMS Microbiol Lett 8, 87-91.

Gerhardt, P., Murray, R. G. E., Wood, W. A. \& Krieg, N. R. (editors) (1994). Methods for General and Molecular Bacteriology. Washington, DC: American Society for Microbiology.

Kämpfer, P. (1990). Evaluation of the Titertek-Enterobac-Automated System (TTE-AS) for identification of members of the family Enterobacteriaceae. Zentralbl Bakteriol 273, 164-172.

Kämpfer, P. \& Kroppenstedt, R. M. (1996). Numerical analysis of fatty acid patterns of coryneform bacteria and related taxa. Can J Microbiol 42, 989-1005.
Kämpfer, P., Steiof, M. \& Dott, W. (1991). Microbiological characterization of a fuel-oil contaminated site including numerical identification of heterotrophic water and soil bacteria. Microb Ecol 21, 227-251.

Kämpfer, P., Dreyer, U., Neef, A., Dott, W. \& Busse, H.-J. (2003). Chryseobacterium defluvii sp. nov., isolated from wastewater. Int J Syst Evol Microbiol 53, 93-97.

King, E. O., Ward, M. K. \& Raney, D. E. (1954). Two simple media for the demonstration of pyocyanin and fluorescein. J Lab Clin Med 44, 301-307.

Kumar, S., Tamura, K., Jakobsen, I.-B. \& Nei, M. (2001). MEGA2: molecular evolutionary genetics analysis software. Bioinformatics $\mathbf{1 7}$, 1244-1245.

Kwon, S.-W., Kim, B.-Y., Weon, H.-Y., Baek, Y.-K. \& Go, S.-J. (2007). Arenimonas donghaensis gen. nov., sp. nov., isolated from seashore sand. Int J Syst Evol Microbiol 57, 954-958.

Peña, A., Valens, M., Santos, F., Buczolits, S., Antón, J., Kämpfer, P., Busse, H.-J., Amann, R. \& Rosselló-Mora, R. (2005). Intraspecific comparative analysis of the species Salinibacter ruber. Extremophiles $\mathbf{9}$, 151-161.

Thompson, J. D., Gibson, T. J., Plewniak, F., Jeanmougin, F. \& Higgins, D. G. (1997). The CLUSTAL_X windows interface: flexible strategies for multiple sequence alignment aided by quality analysis tools. Nucleic Acids Res 25, 4876-4882.

Tindall, B. J. (1990). A comparative study of the lipid composition of Halobacterium saccharovorum from various sources. Syst Appl Microbiol 13, 128-130.

Yang, P., De Vos, P., Kersters, K. \& Swings, J. (1993). Polyamine patterns as chemotaxonomic markers for the genus Xanthomonas. Int J Syst Bacteriol 43, 709-714.

Yokota, A., Akagawa-Matsushita, M., Hiraishi, A., Katayama, Y., Urakami, T. \& Yamasato, K. (1992). Distribution of quinone systems in microorganisms: gram-negative Eubacteria. Bull Jpn Fed Cult Collect 8, 136-171.

Young, C.-C., Kämpfer, P., Shen, F.-T., Lai, W.-A. \& Arun, A. B. (2005). Chryseobacterium formosense sp. nov., isolated from the rhizosphere of Lactuca sativa L. (garden lettuce). Int J Syst Evol Microbiol 55, 423-426.

Ziemke, F., Höfle, M. G., Lalucat, J. \& Rosselló-Mora, R. (1998). Reclassification of Shewanella putrefaciens Owen's genomic group II as Shewanella baltica sp. nov. Int J Syst Bacteriol 48, 179-186. 